\title{
Hydration products of lime-metakaolin pastes at ambient temperature with ageing
}

A. Gameiroa,*, A. Santos Silva a, R. Veigab, A. Velosac

a National Laboratory of Civil Engineering, Materials Department, Av. do Brasil, 101, 1700 Lisbon, Portugal

b National Laboratory of Civil Engineering, Buildings Department, Av. do Brasil, 101, 1700 Lisbon, Portugal

c Department of Civil Engineering, Geobiotec, University of Aveiro, Campus Universitário de Santiago, 3810-193 Aveiro, Portugal

Abstract

Mortars constituted of lime mixtures with pozzolanic additions have been extensively used in the past for the construction of historic and traditional buildings.

This paper presents the results of blended pastes of lime and metakaolin (MK), namely compounds formed and their stability over time. This research is part of an extensive study aiming at the formulation of lime based mortars for restoration purposes.

It has been shown for several years that MK has been applied in inorganic binders due to its capacity to react vigorously with calcium hydroxide $(\mathrm{CH})$. In the presence of water originating a series of major hydrated phases, namely tetra calcium aluminate hydrate (C4AH13), calcium silicates hydrates $(\mathrm{CSH})$ and calcium aluminium silicate hydrates (stratlingite - $\mathrm{C} 2 \mathrm{ASH} 8$ ).

Several blended pastes of lime and MK, with different substitution rates of lime by MK (wt\%) were prepared and cured at a temperature of $20 \circ \mathrm{C}$ and relative humidity $\mathrm{RH}>95 \%$.

The phase composition of the formed hydrated phases was determined by X-ray diffraction (XRD) and simultaneous thermal analysis (TG-DTA).

The obtained results showed that lime/MK pastes compositions displayed different reaction kinetics during curing time, being the pozzolanic products content directly proportional to the substitution rate of lime by MK. Also, a relationship between the increase stratlingite content and the MK substitution rate of lime by MK was found.

Keywords: XRD, TG-DTA, Lime, Metakaolin, Hydrated phase, pozzolanic reactions 